\title{
Research on Classification and Knowledge Construction System of Digital Media Art
}

\author{
Rui Yu \\ Sichuan University of Cultural and Arts \\ Mianyang, China 621000
}

\begin{abstract}
Digital media art is a combination of art and technology, a rapidly developing interdisciplinary subject combining art and technology, and the fusion of computer science, technology, art design and multiple disciplines. Although digital media art is currently developing at a high speed, the professional discipline classification and professional knowledge construction system of digital media art specialty is still unclear. In this paper, the professional discipline classification and professional knowledge construction system of digital media art specialty are sorted out and analyzed, and a clear professional field classification and reasonable professional knowledge construction system are put forward. The field of digital media art specialty covers a wide range of content, and the research of this paper can provide professional colleges and universities with correct teaching activity arrangement and scientific discipline running characteristics. It provides a theoretical reference for digital media art specialty to avoid unclear direction and misunderstanding in research fields and knowledge construction system that may appear in the process of crossdisciplinary development.
\end{abstract}

Keywords-digital media art; application technology; professional fields; knowledge construction

\section{INTRODUCTION}

The digital media arts specialty is an interdisciplinary and comprehensive subject involving arts and sciences. Simply speaking, it is a professional discipline that covers two types of talents: technology and arts. The digital media art is a "new form of art that integrates the rational thinking of human beings with the perceptual thinking of art. The science-based technical talents provide a basic platform for applied talents of liberal arts on the material basis of the scientific and technical support of computers, networks and hardware. The liberal arts-based applied talents use the basic application skills of computer science and technology and the basic knowledge of the digital media art design discipline to build an organic living organism that are above technology, also known as superstructure, and finally complete the digital media art works through reasonable media operations.

\section{PROFESSIONAL FIELD ClASSIFICATION OF DigITAL MEDIA ART}

By combing and summarizing the branch and interrelation of digital media art in professional art, talents of digital media art are divided into two types: science-based technical talents and liberal arts-based applied talents.

- Science-based technical talents: mainly refer to those in the technology-related computer technology field, network technology field and hardware system technology field.

Talents in this professional field needs to master the theory and core technology of digital media, engage in the research and development of digital mediarelated technology, and enrich the expression of media art through computer technology. They use the computer information processing technology to process, acquire, store, disseminate and output text, graphic images, audio and video, animations, etc.

- Liberal arts-based applied talents: mainly refer to those in the field of basic theory and application skills of computer science, art design field and media operation and planning field relevant with culture, art and media.

This professional field integrates culture, art and media, integrates the emotional thinking of art and rational cultural thinking to create and design new forms of expression through new media.

\section{KNOWLEDGE CONSTRUCTION SYSTEM OF SCIENCE- BASED TECHNICAL TALENTS}

\section{A. Computer Technology Field}

It assists the drawing, calculation, modeling and so forth in the creative works of arts in accordance with specific algorithms. Through the comprehensive processing of languages, symbols, image graphics, sound and images, and texts by computer, it has broken through the manual limitations of design traditional art design. Practitioners are required to master the technologies such as the design of mainstream programming, as well as the techniques, system management, database maintenance skills for the development of small application software. As a result, they 
can apply these technologies to the development of software and game engines such as digital media audio processing, graphics image processing, and digital media transmission, virtual and reality, non-linear editing, digital video processing, digital media compressing, and streaming media, etc.

\section{B. Network Technology Field}

It requires practitioners to have the web server configuration, web programming technology, basic development technology for interactive multimedia website, and the development technology for network application system. It applies advanced computer technology to the media art, and combines the media forms based on a certain logical relationship, so that they can interact with each other to gain an experience. It is an important guarantee for the media dissemination art to turn to network communication from language and text, and electronic communication. This technology is more dynamic and interactive. It combines the interactive features with the experiential features, and uses them in the interactive entertainment filed: the development of video games, online games, and installation art, interactive animation, and consumer electronics, etc. At the same time, it applies the digital media resource management, plans and designs the digital media network application scheme, and also utilizes the mainstream media network technology and network application development framework.

The development and popularization of network technology has changed the interaction between people, society, nature and living environment. The network media technology rotates the earth between the "net fingers" to create a virtual reality world for human beings, thus setting up a fast channel for the network in all areas of human life.

\section{Hardware Technology Field}

Hardware refers to the design and manufacture of computers' processing, reservoir, input and output equipment and controllers, etc. It is mainly for the design and analysis of analog circuits and digital circuits, and the application and development of embedded systems.

\section{SKILLS AND KNOWLEDGE CONSTRUCTION SYSTEM OF LIBERAL ARTS-BASED APPLIED TALENTS}

\section{A. Field of Basic Theory and Application Technology of Computer Science}

Talents in this field apply computer science to assist in design, master basic theory and application technology, and skillfully use related professional software technology to support the creation of digital media art works. Based on their own design concept, they input the specific data and design intent required in the design according to the needs to complete accurate processing of graphic image data through the computer software program. During the whole operation, the computer can not only ensure the accuracy of the data, but also reduce the error in the drawing process, while presenting the diverse and flexible color matching of the interface, humanized perspective relations, and multi-angle viewing effects, etc. The computer design software also provides quick and convenient production functions such as memory, replication, saving and modification for the whole operation process, while allows the designers to minimize defects as much as possible. Meanwhile, it provides intuitive and convenient design approaches and production links for the entire design and production process, so that designers can put more energy into design and thinking.

Graphic design software: master the design software of bitmap and appropriate amount of graphics, such as the design of game character and scene, the design of subtitle and font, etc.

Three-dimensional modeling software: design and manufacture three-dimensional models, including the use of mainstream motion capture equipment and corresponding software.

Film and television post-synthesis software: linear and non-linear editing software, understand the encoding and collection method of audio and video signals, and master the use of equipment and working process. It is the comprehensive use of sound effects, special effects, colors and dynamics.

The design and manufacture of web page, design of game character, design of scene.

VR technology: it is an experiential form of artistic expression. The vision brings people into the fantasy world, while the sense of touch gives people an immersive experience. People can enjoy perfect hearing, and even really have the experience of smelling the taste.

\section{B. Art Design Basis Field}

Through the study of traditional art, the creative expression, expression methods, aesthetics, art psychology, art history and art language of art design are cultivated. And then the digital media art creation is completed by mastering the theory of film and television, perspective and threedimensional spatial imagination, etc.

Traditional art is the study of art ontology and creative painting theory. Digital media art professionals must have a certain artistic cultivation, master the basic knowledge such as the sketch, color composition, plane composition, threedimensional composition, art concept, modeling skills, and perspective principles of traditional art, as well as the techniques such as the drawing of the original painting, manual draft design and hand-drawn design, etc. They must have a keen sense in the aspect of aesthetic identification and creative design. In addition, they shall be able to combine and arrange various visual elements to express the visual communication design concept of art works, and understand appreciation and aesthetics.

Basis of art design: Digital media art uniquely displays the artistic style of traditional art works with the help of modern digital technology (science-based technology type) based on the manual operation art of traditional fine arts. It makes use of computer technology to produce graphic design and human-machine interface design, as well as influence the 
animation design, web interface design, scene design, and design of interactive characters in games, etc.

Digital animation, film and television production basis: The application of film and television production has expanded from a professional film and television filed to a wider filed of computer games, multimedia, Internet and home entertainment, etc. Film and television production needs to master photography, camera shooting and audiovisual language theory, and create artistic forms in various files such as image, audio, video and processing. Modern animation design not only requires for involving the previous skills, but also focuses on the principles of dynamics, ergonomics, exploration and research of three-dimensional software and other technical works.

\section{The Humanity CATEgory of Digital Media: PLANNING AND OPERATION MANAGEMENT COMMUNICATION SCIENCE}

The digital media art keeps influencing the audience's emotions, ideas, thought and other spiritual world with the expressive style and cultural connotation of media that it displays. Therefore, digital media planning is an art with humanistic feelings. The creation and planning of digital media art works belong to the preliminary work, so highquality copywriting is particularly important.

Secondly, the propaganda and promotion of productions by the communication science runs through the entire operation management system. In the later period, it is necessary to master the media monitoring, search, filtering and other technologies, and use these technologies to monitor the digital media networks, and protect the digital media art works through the operation management mode such as certification, authorization and copyright protection, etc.

It is not enough to have only one of them. The skills and knowledge construction system of liberal arts-based applied talents not only needs the basic theory and application technology of computer science, but also possesses the creation and innovation ability, artistic culture and creative planning skills and knowledge, skills and knowledge of graphic image software design and production.

VI. SUMMARIZATION OF INFORMATION VISUALIZATION METHODS AND CONCLUSION OF THE STRUCTURE SYSTEM OF Digital Media ART as a Media Product

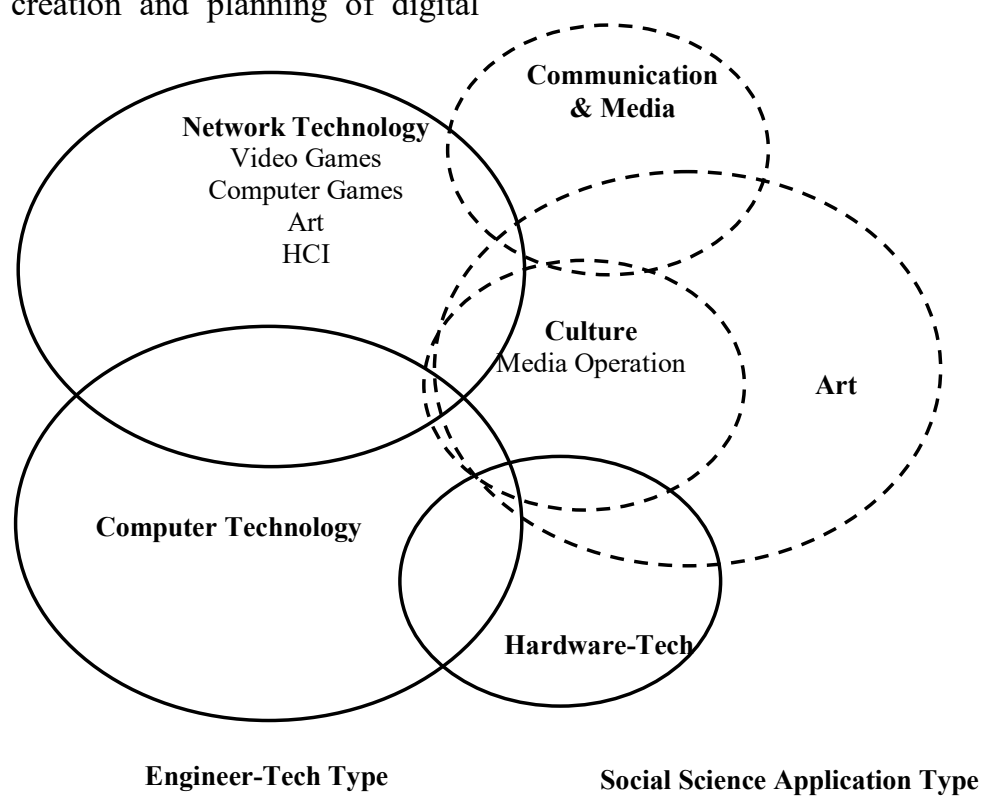

Fig. 1. Classification model of digital media art.

From the above "Fig. 1", it is not difficult to see that the knowledge system between the science-based technical talents and liberal arts-based applied talents is in a relationship of mutual integration, mutual support and mutual utilization. Science and technology are the first productive forces, changing the media and art supporting environment, and digital technology is becoming the basic factor supporting all the media, providing a variety of forms of expressions for art. Culture is the soul of artistic works, and it plans the copywriting of works that are cultural, valuable to social history and human civilization. The expression of artistic symbols is the aesthetic standard of image visual communication. Its elements are cross- symbiotic. The knowledge construction system of a science is not only from a certain factor, and the desired effects can be achieved only through integration of multidisciplinary and multi-knowledge level. It requires people to enhance the aesthetic value of digital media words from different perspectives. But nowadays, there is a misunderstanding of unclear research field and knowledge construction system in the research field of digital media art, resulting in that some science-based technical professions unilaterally replace aesthetic perception with technical analysis. Therefore, understanding the technical performance characteristics of digital media art, guiding the creation of digital art with the guidance of the basic theory of art, and integrating 
technology and art perfectly and cleverly is the true presentation of digital media art. Technology has promoted the development of art, while art has inserted the wings of imagination into technology.

\section{CONCLUSION}

Digital media art is an emerging media form. The development of science and technology has opened up a new situation of art development: massive storage, powerful collection and search functions, accurate information classification computer technology and network technique take effect to achieve precision, digitalization and intelligent development by combining with traditional art. The so-called digital media art is a vivid interactive and coexisting relationship between digital art and technology, between digital media art works and audience, and between virtual and real space. With the virtual characteristics of digital media technology, the digital media art can be used to realize the visualization of technology and build a more colorful virtual world. The unique interactive and fantastic features of media art shall be seized to create digital media art works that meet psychological needs.

Digital media art is a comprehensive discipline integrating virtual art, design art, computer graphic image art and media technology art. Its form of expression is digital media and its content of expression is artistic work. It should be all-inclusive in the choice of subject classification and knowledge construction. The science-based technical talents are good at logical thinking, and can give their superiority into full play in the software programming and the application of big data. The liberal arts-based applied talents have greater advantages in the aspect of expression, appearance design and literature. In the process of studying, we shall clarify the relationship between disciplines, pay attention to the systematicness and science in professional classification, and focus on the research on the crossing field and overlapping field. In addition, we shall make clear the direction and purpose of teaching and accurately position the professional direction to construct a reasonable knowledge structure system, and conduct complementary learning in accordance with the "model" in the fifth chapter of this paper. In terms of our study methods, we shall strengthen the cultivation of scientific, logical and creative thinking and practical ability, improve the professional level and knowledge structure system of digital media art, and enhance the awareness of digital design, so that we can become professional technical talents that have both good scientific and cultural literacy and keen aesthetic vision, and not only possess comprehensive creative thinking methods, but also know well professional technical skills. Only by understanding more clearly the classification of digital media art can we establish a scientific knowledge construction system and promote the development of digital media art.

\section{REFERENCES}

[1] Lingyun Li. Research on the Core Undergraduate Curriculum System of Digital Media Major in China [D]. Wuhan: a master's thesis of Central Normal university, 2008.
[2] Zhongxiang Liao. Theory of Digital Art (Part 1) [M]. Beijing: Beijing Broadcasting and Television Press, 2006.

[3] Sida Li. History of Digital Media Art [M]. Beijing: Tsinghua University Press, 2008

[4] Xiaoyan Qiu. Reflection on the Current Situation of Digital Media Art. Journal of the Southwest University for Nationalities (Humanities and Social Science Edition), 28-12-2003.

[5] http://www.nma.cn/China Digital Media Art Website

[6] Bin Wu. Discussion on the Application of Digital Media Art in Teaching. Journal of Yunnan Arts University, 25-06-211. 